\title{
ARTIGOS
}

\section{Ciclo Hidrossocial e o Reabastecimento Social das Águas: uma experiência na Comunidade Quilombola da Tapera (RJ)}

Ana Caroline Pinheiro Imbelloni*
Universidade Federal de Juiz de Fora (UFJF)

Miguel Fernandes Felippe ${ }^{* *}$

Universidade Federal de Juiz de Fora (UFJF)

Resumo: É inteiramente relevante compreender os movimentos que as águas fazem, desde os movimentos físicos (precipitação, evaporação, infiltração, escoamento, entre outros) até os movimentos sociais, em que os seres humanos causam a sua fluidez. A essa forma de trazer visibilidade também à dinâmica social da água, compreendendo seu caminho refeito por mulheres e homens, chamamos de ciclo hidrossocial. O trabalho propõe compreender os movimentos que as águas fazem na comunidade quilombola da Tapera, que se localiza no município de Petrópolis, região serrana do estado do Rio de Janeiro. A comunidade possui uma relação centenária de autogestão da água em seu território, que, aliás, é amplamente drenado, de forma simbiótica com ambiente, aproveitando a fluidez do rio para trazerem a água para perto de si. Contudo, após as grandes chuvas de janeiro de 2011, houve uma ruptura entre a comunidade e seu território, passando a se reconhecer como a Tapera antes e a Tapera depois das grandes chuvas. Após passarem dois anos fora de suas terras, retornaram ao território reassentados em casas construídas pela prefeitura, em local diferente de antes. A fim de reproduzirem o sistema hídrico urbano, instalou-se um sistema que barra totalmente uma única nascente que abastece toda a comunidade (nascente também escolhida pelos moradores através de seu conhecimento empírico), estocando sua água e disponibilizando para quem ali mora. A relação da população com a água mudou, já que no seu novo ambiente não há água visualmente aparente por seus caminhos, de maneira que o maior contato que possuem é o abrir e fechar das torneiras, como nas áreas urbanas. Assim, uma nascente deixa de se tornar um córrego, mas não deixando de existir e, sim, passando por um caminho socialmente planejado. Esse caminho, como todos os outros caminhos socialmente construídos, precisa ser visto e compreendido para que tenhamos uma melhor gestão e entendimento mais inteiro da movimentação da água que tanto nos é essencial à vida. Palavras chave: Comunidade Tradicional, Ciclo Hidrossocial, Recursos Hídricos.

\section{HYDROSOCIAL CYCLE AND AND SOCIAL REPLENISHMENT OF WATERS: AN EXPERIENCE IN THE TAPERA QUILOMBOLA COMMUNITY (RJ)}

Abstract: It is quite important to understand the movements of water, since physical movements (precipitation, evaporation, infiltration, flow, etc.) even social movements, which humans cause their fluidity. We call the hydrosocial cycle this point of view that brings visibility also to the social dynamics of water, understanding its path redone by women and men. This paper proposes to understand the water movements in the Tapera Quilombola Community, which is located in the municipality of Petrópolis, in the mountainous region of the state of Rio de Janeiro (Brazil). The community has a centennial relationship of self-management of water in its territory, whichis largely drained, taking advantage of the fluidity of the rivers to bring the water closer to themselves. However, after the great rains of January 2011 there was a rupture between the community and its territory, beginning to recognize itself as the Tapera before and the Tapera after the great rains. They only returned to their territory two years after the tragedy, resettled in houses built by the city hall, in a different place than before. In order to reproduce the urban water system, it was installed a system that totally bars one single spring that supplies the entire community, (a spring chosen by the residents through their empirical knowledge), storing water and making it available to residents. The relationship between population and water has changed. In its new environment there is no visible water through its pathways, so that the biggest contact they have is the opening and closing of the taps, as in urban areas. Thus, a spring ceases to become a stream, but not ceasing to exist, but flows through a socially planned path. This path, like all other socially constructed paths, needs to be seen in order to have better management, and a more complete understanding of the movement of water that is so essential to life. Keywords: Traditional Community, Hydrosocial Cycle, Water Resources.

\section{CICLO HIDROSOCIAL Y REABASTECIMIENTO SOCIAL DE AGUA: UNA EXPERIENCIA EN LA COMUNIDAD DE QUILOMBOLA DA TAPERA (RJ)}

Resumen: Es completamente relevante comprender los movimientos que hacen las aguas, desde los movimientos físicos (precipitación, evaporación, infiltración, escorrentía, entre otros) hasta los movimientos sociales, en los que los seres humanos causan su fluidez. Esta forma de dar visibilidad también a la dinámica social del agua, entendiendo su camino renovado por mujeres y hombres, lo llamamos ciclo hidrosocial. El trabajo propone comprender los movimientos que realizan las aguas en la comunidad quilombola de Tapera, ubicada en el municipio de Petrópolis, región montañosa del estado de Rio de Janeiro. La comunidad tiene una relación centenaria de autogestión del agua en su territorio, que, por cierto, se drena en gran medida, simbióticamente con un entorno que aprovecha la fluidez del río para acercar el agua a sí misma. Sin embargo, después de las fuertes lluvias en enero de 2011, hubo una ruptura entre la comunidad y su territorio, comenzando a reconocerse como Tapera antes y Tapera después de las grandes lluvias. Después de pasar dos años fuera de sus tierras, regresaron al territorio reasentado en casas construidas por el ayuntamiento, en un lugar diferente que antes. Para reproducir el sistema de agua urbano, se instaló un sistema que bloquea completamente un solo manantial que abastece a toda la comunidad (unmanantial también elegido por los residentes a través de su conocimiento empírico), almacenando su agua y poniéndola a disposición de quienes viven allí. La relación de la población con el agua ha cambiado, ya que en su nuevo entorno no hay agua visible en sus caminos, por lo que el mayor contacto que tienen es la apertura y cierre de los grifos, como en las zonas urbanas. Por lo tanto, una fuente deja de convertirse en una corriente, pero no deja de existir, sino que pasa por un camino socialmente planificado. Este camino, como todos los otros caminos construidos socialmente, necesita ser visto y entendido para que tengamos una mejor gestión y una comprensión más completa del movimiento del agua que es tan esencial para la vida. Palabras-llave: comunidad tradicional, ciclo hidrosocial, recursos hídricos.

*Geógrafa. Mestranda no Programa de Pós Graduação em Geografia da Universidade Federal de Juiz de Fora. Rua José Lourenço Kelmer, s/n - Campus Universitário - Bairro São Pedro - CEP: 36036-900 - Juiz de Fora - MG. Email: carol_imbelloni@hotmail.com. ORCID: 0000-0002-5114-2231.

**Professor Doutor. Professor Adjunto do Departamento de Geociências da Universidade Federal de Juiz de Fora/ICH. Rua José Lourenço Kelmer, s/n - Campus Universitário - Bairro São Pedro - CEP: 36036-900 - Juiz de Fora - MG. E-mail: miguel.felippe@uff.edu.br. ORCID: 0000-0002-0261-4298. 
Apresentação da relevância do ciclo hidrossocial e da Tapera

A água é uma grandiosidade no planeta Terra, ocupando a maior parte de sua extensão e sendo uma das grandes responsáveis pela manutenção de diversas formas de vida, inclusive a vida humana. É fundamental que os seres humanos compreendam suas formas, estados, lugares, caminhos, movimentos e ciclos, pois nossa vida é totalmente dependente dela.

Hoje, a forma mais usual de compreender os movimentos das águas é por meio do ciclo hidrológico, pelo qual são sugeridos os lugares onde a água pode estar, fluindo e se reciclando por diversos ambientes, propondo movimentos como a evaporação, precipitação, transpiração das plantas, percolação, infiltração e drenagem (TUNDISI, 2003).

Trata-se de um modelo' muito respeitado por conseguir sintetizar, simplificar e representar processos tão complexos como os das águas. Contudo, ele não leva em conta um fator também muito importante nesses movimentos: homens e mulheres, capazes de movimentar a água de uma localidade à outra através de variadas formas. Podemos observar isso através de exemplos como a canalização, envasamento de garrafas e sua distribuição, construção de fossas e represas, abastecimento de caminhões pipas que fazem o transporte da água de um lugar a outro, a irrigação, assim como o deslocamento dos alimentos que são constituídos por água e que chegam às mesas dos mais diversos tipos de pessoas. Estamos envolvidos no processo da movimentação da água e é muito importante que isso seja visto (PORTO-GONÇALVES, 2013). Sobre isso, Felippe (2010) exemplifica:

Sob a ação humana, a água captada em um determinado local, rompe o ciclo hidrológico de sua bacia de origem, entra em novo ciclo de movimento [...] para incorporar-se em outra bacia, englobando um novo ciclo hidrológico espacialmente desconectado do primeiro. Transposições de bacias hidrográficas, neste contexto, são comuns e as modificações qualitativas e/ou quantitativas da água de determinada unidade espacial ocorrem a todo tempo 2 (p.7, tradução dos autores).

Pensando a partir destes processos, os movimentos das águas passam a ser invisíveis dentro do ciclo hidrológico, não permitindo uma compreensão holista

1 Quem pensou o ciclo hidrológico? Aqui cabe enfatizar que ele não é algo "dado pela natureza" e atemporal como costuma ser apresentado. Ele é um modelo, criado por um homem, em um espaço/tempo, e inserido em um contexto social. Segundo Linton (2006), foi o estadunidense Robert Elmer Horton, em 1931 o primeiro a falar sobre esse conceito, sendo assim, interessante compreender que o ciclo hidrológico é uma construção social.

2 No original: "Bajo la acción humana, el agua captada en un determinado local, rompe el ciclo hidrológico de su cuenca de origen, entra en nuevo ciclo de movimiento [...] para incorporarse en outra cuenca, englobando un nuevo ciclo hidrológico espacialmente desconectado del primero. Transposiciones de cuencas hidrográficas, en ese contexto, son comunes y las modificaciones cualitativas y/o cuantitativas en el agua de determinada unidad espacial ocurren a todo tiempo" (FELIPPE, 2010, p.7) de sua fluidez e de seus caminhos, sendo um grande problema para a gestão das águas. Além disso, ao assumirmos que as forças sociais interferem no ciclo da água, estamos trazendo à luz questões políticas e econômicas, forças motrizes desses "novos" caminhos que a água percorre (SWYNGEDOUW, 1997; SWYNGEDOUW, 2006). Linton (2006) propõe a ideia de abastecermos de social o conceito das águas que há um tempo tem se esvaziado das ciências hidrológicas.

Tendo em vista estas questões, propõe-se um novo olhar sobre as águas: o ciclo hidrossocial. Esse conceito parte das concepções do ciclo hidrológico (entendido pela lógica tradicional-cartesiana), contudo o critica e o supera, ao contextualizar o movimento da água na esfera política, social, econômica e cultural (IMBELLONI e FELIPPE, 2017).

O ciclo hidrossocial considera que a água é manipulada através de fatores como obras hidráulicas, legislações, instituições, práticas culturais e significados simbólicos (BUDDS; HINOJOSA, 2012). Compreendendo a amplitude e as possibilidades, podemos ter uma visão muito mais ampla sobre a fluidez (ou não) da água. Assim, promove a compreensão de que a sociedade molda e é moldada pela água, possuindo um papel dinâmico e ativo nas relações sociais (LINTON E BUDDS, 2014; BAKKER, 2012). As formas pelas quais a água flui ao longo do espaço e do tempo também são moldadas por alguns agentes como instituições, práticas e discursos humanos que determinam modos de controle e gerenciamento e a fluidez da água é direcionada também de acordo com os fluxos do capital, ou seja, "flui de acordo com forças políticas e hidrológicas" (LINTON E BUDDS, 2014, p. 172, tradução dos autores) ${ }^{3}$. Conformamos a ideia, então, de que a água é ao mesmo tempo um fluxo físico e também social, um processo híbrido que se relaciona internamente (SWYNGEDOUW, 1997).

Compreendendo esse novo e relevante ponto de vista dos movimentos das águas, que rompe o olhar tradicional trazendo visibilidade também ao componente social, temse uma questão instigante: o que podemos "descobrir" ou aprender ao vermos os movimentos sociais da água sob essa nova perspectiva? O objetivo deste trabalho é (re)desvelar o ciclo hidrossocial dentro do território da Comunidade Quilombola da Tapera, no município de Petrópolis (RJ), relatando e interpretando a complexa relação águasociedade no tempo-espaço da comunidade.

Na Tapera, vive uma comunidade rural que é quilombola e centenária na região. Se localiza no extremo leste do município de Petrópolis, no limite com o município de Teresópolis, região serrana do estado do Rio de Janeiro. A comunidade constitui-se por 19 famílias, totalizando um número de 69 pessoas. Contudo, neste trabalho daremos

3 No original: "flows in accordance with forces that are political as well as hydrological" (LINTON; BUDDS 2014, p.172) 
foco ao núcleo central da Tapera, a zona mais habitada, que dentre o número apresentado se encontram 14 dessas famílias, sendo 65 pessoas.

Eles vivem em um território cercado por morros, com vegetação de Mata Atlântica, em uma bacia muito bem delimitada pelos altos topográficos, densamente drenada e onde nasce o Rio Santo Antônio, importante rio da região de Itaipava (que possui um longo histórico de inundação durante os períodos de chuva). Historicamente, fizeram uso das águas superficiais (rios e nascentes), para os mais diversos fins, sob uma lógica "não capitalista" de produção, o que torna de grande relevância compreender as relações hidrossociais na comunidade.

Uma profunda alteração no ciclo hidrossocial da comunidade foi promovida pelas severas chuvas na região serrana do estado do Rio de Janeiro em janeiro de 2011. O INMET registrou, às 00:00h do dia 11, uma precipitação com volume de $73 \mathrm{~mm}$. Nesta noite, muitas casas foram atingidas e as vidas das pessoas foram mudadas completamente. A comunidade tem essa tragédia como um marco espaçotemporal, de forma que hoje ao falarem sobre suas histórias falam com distinção sobre a "Tapera antiga" (a de antes das grandes chuvas de 2011) e a "Tapera nova" (a de depois das chuvas, principalmente depois da comunidade reassentada) como evidencia a Figura 1. É sobre a compreensão do ciclo hidrossocial dessa comunidade, nos seus dois momentos, que trataremos aqui.

Figura 1: Localização de casas da Tapera antiga e Tapera reassentada

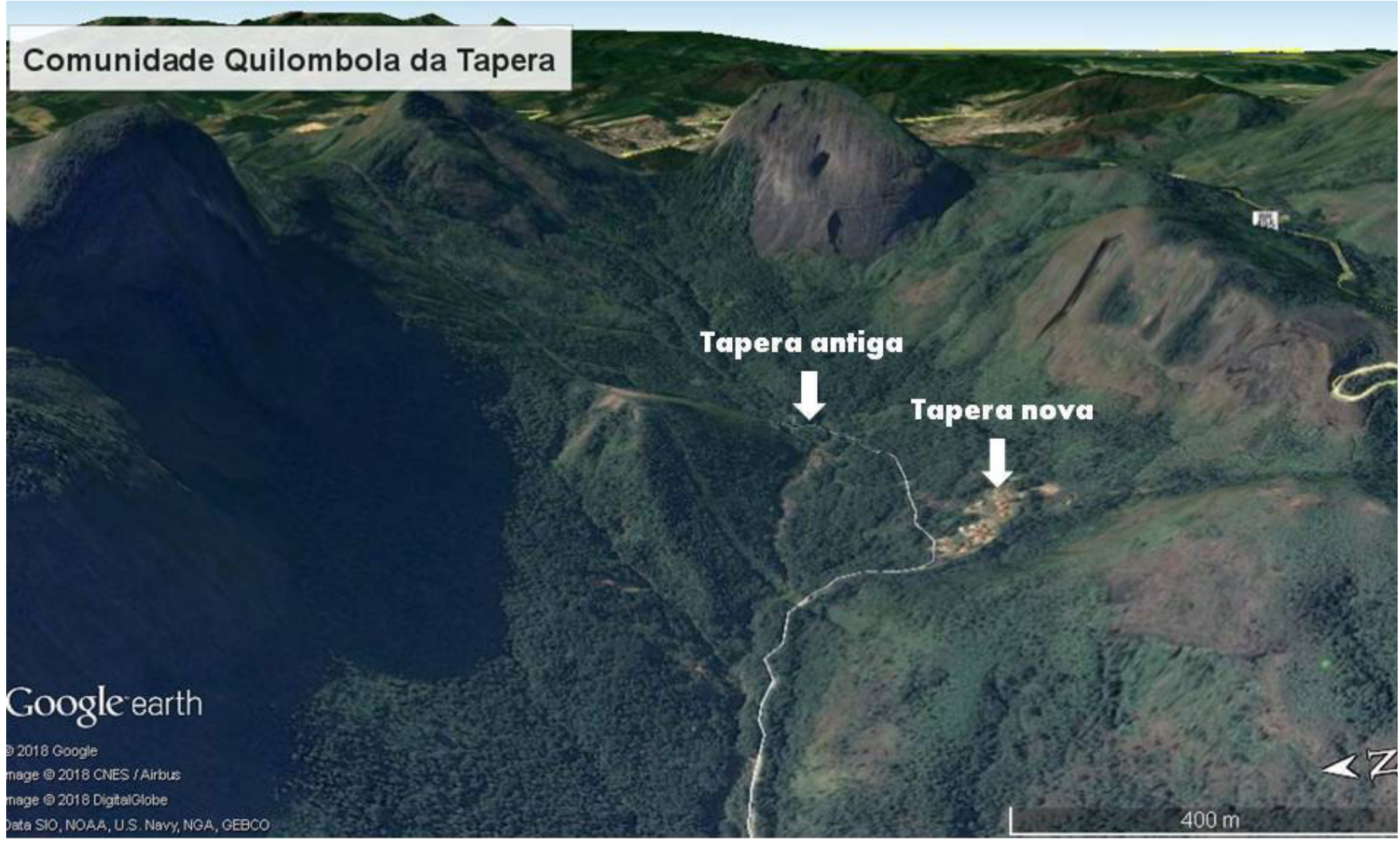

Fonte: Google Earth, março de 2018.

\section{Escolhas metodológicas}

Uma vez que as teorizações acerca do ciclo hidrossocial ainda são recentes, há poucos trabalhos que apontam sobre os procedimentos utilizados para sua investigação. Sem um roteiro que auxilie nessa descoberta, foi necessário "desbravar" técnicas que auxiliariam neste processo, a partir de ferramentas de democratização do discurso que dão protagonismo à comunidade. Optou-se aqui pela união de três técnicas distintas: a comunicação participativa, a cartografia social e a caminhada guiada, de forma que cada uma tem sua contribuição e se complementa no (re)conhecimento do ciclo hidrossocial da Tapera.

A Comunicação Participativa (MELLO, 2006; GARSKE, 2016) é uma técnica desenvolvida pelo CREA (Centro Especial de Investigação em Teorias e Práticas Superadoras de Desigualdades), na Universidade de Barcelona, na Espanha, que tem como centro de suas discussões teóricas e metodológicas o conceito de dialogicidade de Paulo 
Freire e a teoria da ação comunicativa de Jürgens Habermas (GARSKE, 2016; MELLO, 2006).

$\mathrm{Na}$ comunidade, esta técnica foi utilizada a partir da discussão comunicativa e das entrevistas realizadas de forma coletiva ${ }^{4}$, reunindo a população interessada na pesquisa e fazendo uma série de perguntas que guiavam a conversa. Depois deste momento, a conversa foi transcrita e, em um segundo encontro, foi relida para a comunidade a fim de compreender se a história foi compreendida da forma correta. Neste momento foram ajustadas as divergências de entendimento, tirando dúvidas e acrescentando novos itens à conversa.

Esta metodologia propõe uma comunicação dialógica, onde a pesquisadora esteja "em pé de igualdade" com os participantes e, através do diálogo, construam juntos as melhores ideias acerca do objeto de estudo. Esta segunda etapa é muito importante para que os participantes tenham a palavra final sobre o que foi conversado, uma vez que durante a comunicação podem haver diversas distorções de compreensão da fala. Por meio desta técnica, foi possível obter reflexões mais profundas sobre a comunidade, bem como detalhar suas mudanças ao longo do tempo, compreendendo também a influência das águas e a gestão hidráulica comunitária.

Com a cartografia social foi possível conhecer as questões espaciais e os diversos componentes que interagem na comunidade, uma vez que dificilmente seria possível sua compreensão utilizando apenas a comunicação participativa. Importante ressaltar que ela possui uma dinâmica mais horizontal, que se diferencia da cartografia tradicional, sugerindo que os mapas sejam elaborados em conjunto com a população.

Segundo Meireles, Souza e Lima (2016) esses mapas são repletos de representações e relatos sobre os sistemas sociais, econômicos, culturais e ambientais, de uso tradicional, apresentando a soberania territorial de seus grupos. Em entrevista, Alfredo Wagner (LIMA; RAMOS e SILVA, 2013) diz que esta técnica auxilia as comunidades na construção de suas memórias e no restabelecimento de suas identidades.

A metodologia da cartografia social foi desenvolvida em diferentes etapas que serão descritas a seguir. $O$ primeiro ato foi a apresentação para a comunidade do que é um mapa, sua importância, como interpretá-lo, a produção e construção de mapas sociais de outras comunidades tradicionais. O segundo momento possui grande relevância por ser o dia da elaboração dos mapas pela comunidade. Para sua feitura foram utilizados: papel vegetal, mapa impresso com imagem do Google Earth e o próprio Google Earth, em

4 A técnica sugerida para entrevista é de que seja individualizada, segundo Garske (2016), contudo optou-se por adaptá-la para que fosse coletiva e assim conversar, discutir e construir com toda a comunidade ao mesmo tempo sobre suas histórias e sua organização social e espacial. funcionamento, para facilitar a marcação de alguns pontos que não eram visíveis no mapa impresso. Cabe destacar que a ferramenta permite a troca de imagens ao longo da série histórica possibilitando a visualização de detalhes dentro do mapa.

A terceira etapa deste processo compreendeu a inserção das coordenadas registradas em campo com o receptor de GPS de pontos que não foram possíveis de marcar no mapa. A elaboração do mapa digital, georreferenciando as marcações registradas e digitalizando as legendas desenhadas foi o quarto momento. As últimas fases do processo se deram no retorno à comunidade para o aval sobre o mapa elaborado e, após isso, a entrega do mapa final. Com esta técnica foi possível observar a extensão da comunidade, ver os cursos d'água relevantes para eles, entender a organização espacial e social comunitária, perceber o entendimento sobre o seu território e o quanto são saudosos quanto ao lugar antes ocupado.

A caminhada guiada sugerida por Budds (2012) consiste em uma caminhada com um ou mais moradores da comunidade pelo território em que ocupam. Com esta técnica foi possível entender melhor as dinâmicas espaciais, aprofundar histórias remetidas ao lugar e também ver as paisagens do local. Nesta pesquisa, houve duas caminhadas pela comunidade com um morador, o que permitiu o registro de coordenadas não vistas na cartografia social (por estarem encobertos pela mata, por exemplo), além de permitir visualizar as paisagens e passar pelas ruínas e casas dos moradores na Tapera antiga. A caminhada guiada foi essencial para compreender melhor a construção social e o desdobramento de suas vidas, os impactos causados pelas chuvas, as antigas relações e o ambiente como se apresentava e se apresenta, assim como a nova forma de organização que passaram a ter no reassentamento onde vivem hoje.

Estas três metodologias se complementaram e contribuíram para um melhor entendimento e percepção da organização espacial da comunidade e da água, assim como as histórias e narrativas envolvidas para a construção da comunidade e seu ciclo hidrossocial.

\section{A relação entre a comunidade, água e seus movimentos}

O marco temporal "antes e depois da tragédia", apresentado pelos moradores, de fato, é muito significativo, pois a vida da comunidade mudou completamente, inclusive suas relações hidrossociais, repercutindo na interação dos homens e mulheres com a água, a incluir sua construção social e seu manejo. Ao pensar que há 172 anos a comunidade da Tapera se constituiu, organizou-se como território e fez de lá seu lugar, é possível imaginar as muitas relações criadas naquele espaço e, entre essas, os diversos entrelaces com a água. A Figura 2 é o mapa social desenvolvido com a 
comunidade e aponta a ideia de organização comunitária juntamente com os elementos relevantes para os moradores, a vegetação, as plantações, os cursos d'água que banham o território quilombola, as estradas e diversas outras informações.

Figura 2: Mapa da Comunidade elaborado a partir da Cartografia Social

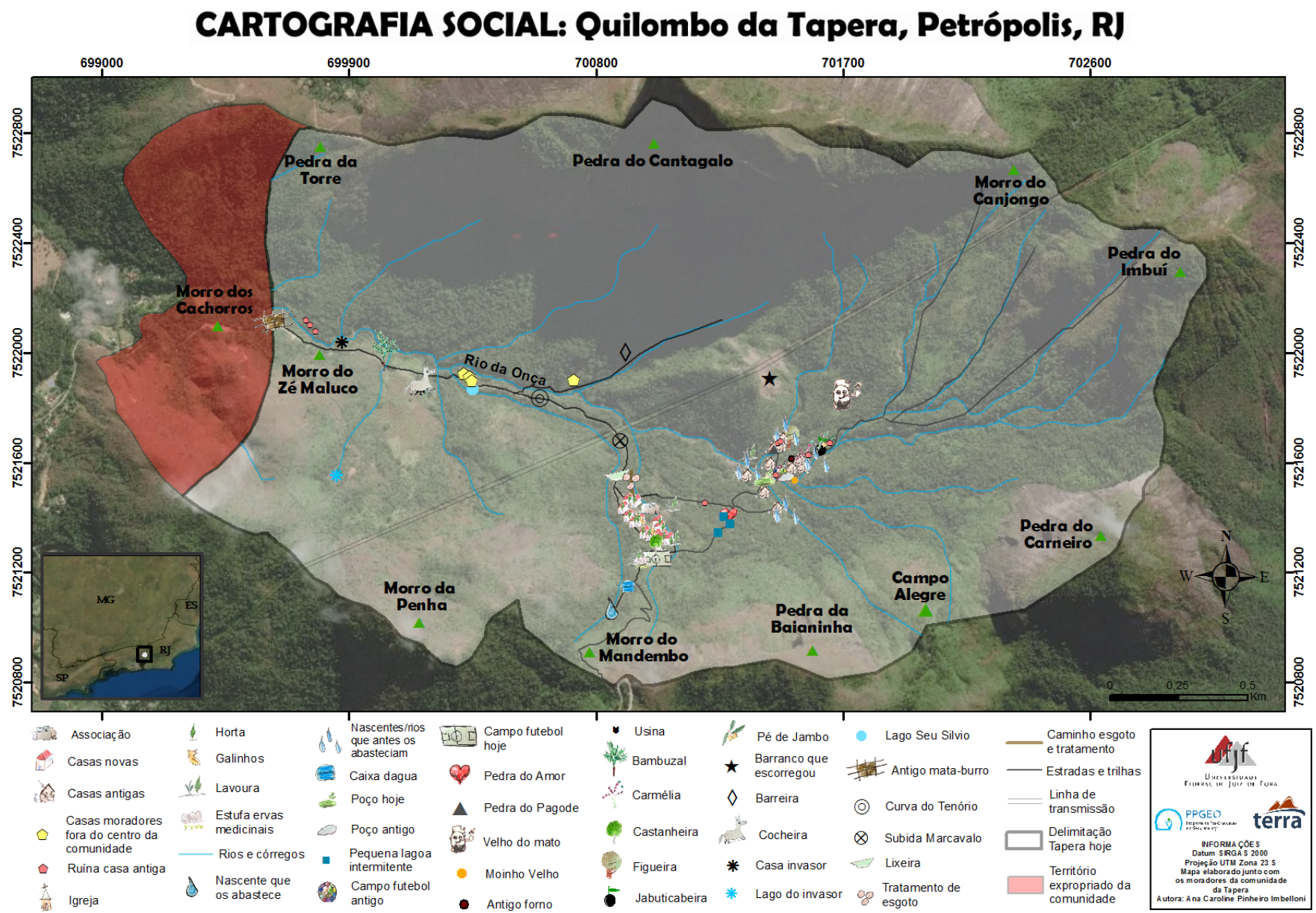

Fonte: Elaborada pelos moradores da comunidade da Tapera e pela autora, dezembro de 2018.

Como Budds (2009, 2012), Linton (2006, 2014) e Swyngedouw $(1999,2005)$ dizem, a água possui dimensões sociais e físicas inseparáveis e sobre essas relações surge a proposta de reflexão: como os fluxos das águas constroem/são construídos na comunidade da Tapera? Para compreender a relação da comunidade com a água e com seu espaço não é possível desvincular sua história. É também necessário contextualizar o espaço/tempo do qual falamos: a Tapera antes das chuvas (como a comunidade era antes do grande temporal de janeiro de 2011) e a Tapera depois das chuvas de 2011 (principalmente após o reassentamento), já que a relação entre água e comunidade são distintas nestes dois momentos. Sobre isso trataremos a seguir.

\section{Tapera antes das chuvas de janeiro de 2011}

É importante contextualizar a construção da forma de vida da comunidade e a forma como lidavam com o espaço e o ambiente antes das grandes chuvas de 2011. As pessoas que viviam na Tapera possuíam uma forma própria de se organizar, modo este construído ao longo dos 172 anos em que a comunidade começou a existir. Ao longo desses quase dois séculos, aprenderam a manejar a terra, a água, escolheram a melhor localidade para construir suas casas e isso sempre próximos aos cursos d'água. As famílias foram crescendo e novas casas foram surgindo, feitas geralmente próximas ao núcleo familiar. As terras não eram demarcadas por cercas, era implícito que cada área daquela pertencia a determinada família.

As casas eram feitas de pau-a-pique e normalmente construídas com o trabalho coletivo e comunitário. Os primeiros telhados eram de sapê e, no último século, passou a ser de telhas pré-fabricadas (eram carregadas por cavalos até lá). Em um passado mais recente, começaram a existir 
casas de alvenaria na comunidade. Até 2011, não havia luz elétrica disponível para os moradores, ainda que muitos demandassem ao poder público, sem sucesso. Algumas famílias faziam uso de geradores movidos à combustíveis fósseis. Anteriormente, havia um gerador movido à água, mas pouco funcionou na época, até se tornar inutilizado disseram que a água do rio foi diminuindo cada vez mais com o tempo.

Antes viviam da plantação de espécies de leguminosas e verduras. Também criavam galinhas e porcos que serviam para alimentação. Disseram que podiam até não ter tudo que gostariam de comer, porém, fome nunca passaram. Plantavam por toda redondeza da Tapera e cada parte de seu território tem um nome ensinado pelos mais velhos. Cabe ressaltar que, segundo eles, normalmente não era preciso irrigar a plantação, salvo exceções ${ }^{5}$.

Após o pequeno contexto sobre como se organizavam, falaremos diretamente sobre o manejo das águas, aplicado pela população, que foi aprendido com seus ancestrais. Sobre isto Swyngedouw (1997) nos lembra de que a água também é manipulada, ou altera seu ciclo "natural" através de fatores como obras hidráulicas a serem exposta a seguir.

As casas $^{6}$ eram construídas estrategicamente próximas aos rios e a comunidade tinha uma forma de manejo própria das águas. Mesmo ao lado dos cursos d'água, a comunidade possuía um sistema hidráulico que permitia que a água chegasse ao quintal de todas as casas.

$\mathrm{Na}$ Tapera antiga ${ }^{7}$, os moradores construíam pequenas valas que permitiam a passagem das águas (formando pequenos filetes de água) até algum grande obstáculo chegar. Após trazer as águas o mais próximo possível de suas casas através das valas, eles encanavam a água no tronco de algumas árvores, como embaúba ou bambu, cortadas ao meio, fazendo canaletas sobrepostas e suspensas por troncos (que suspendiam as caneletas, firmando-se no chão) até chegarem às respectivas casas.

Já na Tapera antiga mais recente ${ }^{8}$, encavam a água com mangueiras desde o rio até suas casas. No caminho, a mangueira era enterrada para manter a temperatura da água e também passava por matas, de forma a deixá-la o máximo possível fresca.

Ambos os tipos de sistema hidráulico precisavam de manutenções, principalmente quando chovia muito, pois as estruturas das canaletas ficavam um tanto "mexidas", assim

5 Como o brócolis da região onde vivem hoje que diz respeito a um passado mais recente onde falaremos isso mais a frente.

6 Aproximadamente 13 treze casas. O número de perde por haverem muitas ruínas de casas não mais utilizadas, inclusive por falecimento. Esse número foi baseado no número de casas novas entregues às famílias após a tragédia.

7 Tapera dos pais e avós dos moradores mais velhos.

8 Período que os moradores que participaram da pesquisa viveram até pouco antes das grandes chuvas. como as mangueiras saiam do lugar. Ambos os modelos também buscavam água mais a montante de suas casas, utilizando somente a gravidade. O relevo da Tapera ajudou muito, uma vez que as casas se localizavam no fundo do vale e estavam cercadas por morros muito bem drenados.

As duas formas de abastecimento também tinham, em comum, a necessidade de utilizar e beber a água "barrenta" após grandes chuvas, já que não estocavam muita água. Contudo, não demorava muitos dias para clarear novamente (ter menos partículas em suspensão, carreada pelas chuvas ao erodir o terreno).

As águas jorravam o dia todo por essas bicas (como chamam os moradores), no quintal de cada uma das casas. Bebiam essas águas assim como a utilizavam para o funcionamento e manutenção da vida doméstica: cozinhavam, lavavam a louça e a roupa, limpavam a casa, banhavam-se, entre outras coisas.

As louças eram lavadas em casa, dentro de caixote de madeira, bacia de alumínio ou fogão velho. A roupa era lavada próxima à bica e ao batedor 9 . Há relatos que moradores mais antigos chegaram a lavar a roupa no rio.

Quanto ao banheiro, na Tapera mais antiga, a maioria dos banheiros não ficava dentro de casa. Para fazerem suas necessidades fisiológicas, os moradores iam para a mata. Para se banhar (que não era hábito diário, inclusive levando em conta a queda da temperatura do ambiente em determinadas épocas do ano), os moradores costumavam fazê-lo no próprio quarto, numa espécie de bacia ou banheira, esquentando água no fogão à lenha e com um pequeno pote colocavam a água sobre seu corpo e esfregavam com sabão. Nos dias em que não tomavam o "banho completo", diziam lavar as partes íntimas, pés e mãos.

Um pouco antes da tragédia das chuvas, muitas casas já possuíam banheiros (mas não todas). Das casas que possuíam banheiros, o banho já era realizado neste novo local e poderia ser frio através da ducha ou quente pelo chuveiro, mas apenas duas casas tiveram chuveiro quente, através de uma engenharia pensada por um morador que através de uma serpentina que passava próxima ao fogão à lenha permitindo o aquecimento da água. Disse que a água do chuveiro jorrava o dia inteiro e muitos vizinhos tomavam banho quente na casa deles. Os moradores que possuíam banheiro dentro de casa construíram fossas para lançar a água utilizada ali. Cabe ressaltar que poucos moradores possuíam caixa d'água, ou seja, poucos armazenavam a água que vinha do rio. A caixa d'água servia como auxílio principalmente na descarga do vaso sanitário. Muitas casas passaram a ter pias também. Com exceção da água do banheiro que ia para a fossa, toda água utilizada no restante das tarefas, chegava pela bica e passava por uma vala, retornando para o rio.

Ao ouvir esses relatos, pode-se perceber que o rio continuava o fluxo normal, cada um trazia um pouco de 
água para perto de si, águas vindas de diversos córregos e locais distintos. Essas águas eram parcialmente desviadas para suas casas (enquanto a maior parte do fluxo seguia seu caminho normal) e após o uso eram devolvidas ao rio, mais a jusante. A água seguiu um fluxo além do percurso que o ciclo hidrológico propôs, o fluxo social, e isso não deve ser invisibilizado. A Figura 3 é um croqui elaborado que aponta os fluxos d'água.

\section{A Tapera no dia das grandes chuvas}

Como Linton e Budds (2014) dizem, o ciclo hidrossocial é um processo social e natural concomitante onde a água e sociedade se (re) produzem mutuamente, fazendose e refazendo-se ao longo do espaço e do tempo. A comunidade da Tapera, como natureza, esteve presente no abrupto processo que alterou parte do desenho dos rios e morros do seu espaço, com isso sua forma de vida mudou. As chuvas que ocorreram na madrugada de 11 de janeiro de 2011 mudaram de forma intensa a construção e constituição da comunidade, tanto seus lugares, sua organização espacial, seus sistemas hidráulicos e a paisagem local, que seria alterada profundamente.

Segundo o relato dos moradores, naquela noite a chuva estava muito forte. Começaram a se comunicar sobre o

\section{Figura 3: Croqui do Ciclo Hidrossocial na Tapera Antiga}

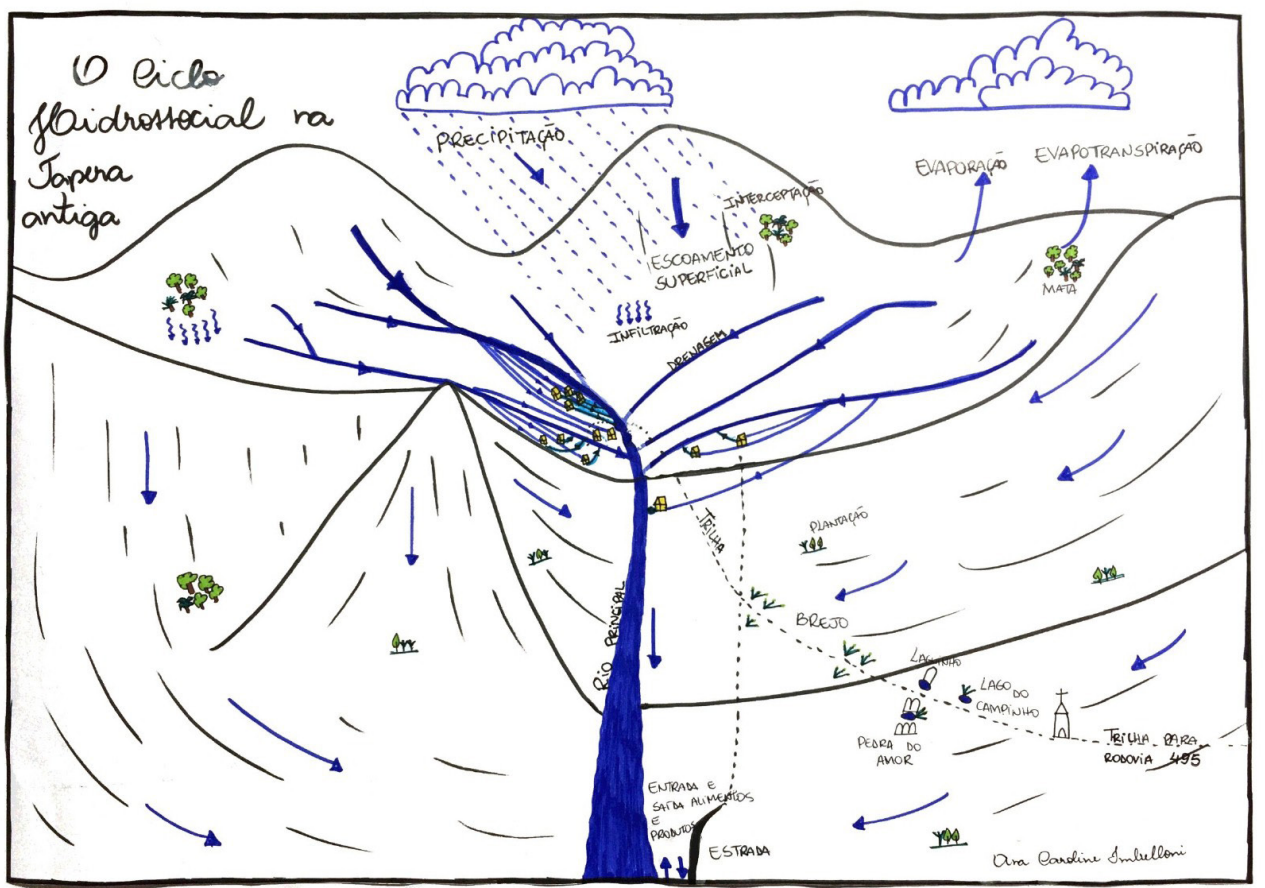

Fonte: Elaborado pela própria autora, abril de 2019.

altíssimo nível do rio através do pouco sinal de celular que ainda tinham. Como não havia luz, era nos relâmpagos que eles conseguiam enxergar o nível da água do rio. Os moradores que estavam na parte mais baixa (cerca de duas ou três casas) logo precisaram sair para se abrigar em outro lugar por causa do aumento do volume das águas. Os moradores que moravam a uma relevante distância acima do nível do rio também precisaram sair de suas casas, pois muita água também descia pela encosta ao lado de suas casas. Disseram que foi uma noite longa, onde sentiram a terra tremer. Como intensificador, houve o escorregamento de uma encosta bem próxima ao centro da comunidade que provocou um fluxo de lama (estava à montante) e que encontrou a calha do rio, que já estava com muita energia e altíssima vazão. A energia dessa água drenada conseguiu alterar consideravelmente as margens e o leito dos rios, erodindo e entalhando-os, assim como quebrando e levando consigo matacões rochosos que se encontravam no leito do rio desde que a comunidade da Tapera começou a existir. Felizmente, nenhum morador perdeu a vida ou se feriu gravemente.

Ao clarear, conseguiram ver como aquela grande chuva redesenhou a Tapera que conheciam, inclusive fragilizando a estrutura das casas de muitos moradores, e levando o que tinham dentro de suas casas (que se foram com a força da água). Os caminhos que existiam foram fechados e, por isso, por cerca de dois dias ficaram sem socorro, pois nem os helicópteros conseguiam um local para pousar. Nesses dias se abrigaram nas casas dos moradores que viviam na parte mais alta e não foram atingidos, onde compartilharam suas roupas, cama e comida.

Após serem resgatados, ficaram uns dias na casa da patroa de um morador da Tapera que providenciou um local para a comunidade se alojar. Fez a reforma em um 
antigo estábulo ${ }^{10}$ que havia ali perto, construindo banheiros e cozinha para que a comunidade vivesse até que a Tapera fosse reconstruída, como forma de abrigo improvisado. Cerca de 10 famílias viveram ali por aproximadamente dois anos, cabendo ressaltar que pagavam aluguel pelo espaço ${ }^{11}$. Outros moradores optaram por alugar casas em outros bairros. Em 23 de outubro de 2013 as novas casas construídas pela prefeitura e pela comunidade (que colaborou com a mão de obra em alguns momentos) ficaram prontas e a comunidade voltou a morar na Tapera, todos reunidos novamente.

Nesses dois anos ficaram "presos" no sistema hídrico urbano, onde não viam mais o rio nem de onde vinha sua água, tampouco para onde ia.

\section{3: O Reassentamento da nova Tapera e a} reconstrução hidrossocial

A água possui papel dinâmico e ativo em sua multiplicidade de estados, formas, espaços, materialidades e temporalidades, servindo para moldar diferencialmente as relações sociais (BEAR e BULL, 2011). A nova Tapera viu esse papel dinâmico da água mudando sua forma de vida e suas espacialidades e viu, também ela, mudando suas novas formas de relações sociais, como veremos mais adiante.

De acordo com os moradores, na nova Tapera eles puderam escolher a área onde morariam e a localização de cada casa, escolhendo inclusive morar ao lado de seus familiares mais próximos (como faziam na organização antiga das casas).

A empresa concessionária (Águas do Imperador) pediu indicação sobre o melhor local de coleta de água para fazer a instalação das caixas d'água e do sistema de abastecimento para a nova Tapera. Os moradores então sugeriram a atual nascente que hoje utilizam com base na experiência de um primo dos moradores (que são parentes) que há anos plantava brócolis naquela área. Para plantar, ele precisava de bastante água, pois segundo os moradores, a irrigação era feita $24 \mathrm{~h}$ por dia, por todos os dias do ano, e a água nunca lhe faltou, mesmo com o crescimento da plantação. A partir da empiria, os moradores perceberam que naquela área havia uma nascente com boa vazão e perene, logo, conseguiria dar conta de abastecer a comunidade também.

A empresa Águas do Imperador construiu um projeto que funciona assim: a água da nascente é cercada através de um pequeno represamento que permite que ela seja encanada e lançada em um tanque maior coberto por telas que impedem que folhas e animais caiam/entrem na água

10 Os moradores disseram que ela procurou alguma casa ou galpão próximo, porém não encontrou.

11 Importante esclarecer que a pessoa que fez a reforma no estábulo (patroa de um dos moradores) não é a mesma que é dona do estábulo e que cada família pagava o aluguel com o Aluguel Social que é um benefício recebido pela prefeitura de Petrópolis às famílias atingidas pela chuva. e também permite que os sedimentos vindos se depositem no fundo do tanque (nesse tanque há um ladrão para dias com vazão excessiva). Dali, a água segue encanada até três caixas d'água de 10.000 litros cada, que são compartilhadas e que acumulam a água liberada pela nascente. A partir deste momento, a água é distribuída para cada uma das 14 casas, onde há caixas de 1.000 litros, chegando, então, às suas torneiras.

Percebe-se que neste novo processo de manipulação hidráulica construído pela empresa concessionária, a comunidade se afasta do percurso da água, como numa área urbana em que a vemos pela torneira e logo nos perdemos do seu novo trajeto. Desta maneira, entende-se que a área rural passa a tratar a água de forma diferenciada e isso não necessariamente por escolha dos habitantes da Tapera, mas sim por um projeto vindo de fora. Outro ponto a ser questionado é a vulnerabilidade da população que agora fica à mercê de apenas uma nascente para abastecer toda comunidade. Caso essa nascente falte, toda a comunidade sentirá, pois, 64 pessoas são totalmente dependentes apenas desta fonte de água (diferente da abundância de água que "regava" a Tapera antiga).

A outra etapa do percurso são as águas residuais de louça, banho, lavagem de roupa (águas cinzas) ${ }^{12}$ e a água dos sanitários que saem das casas, que se juntam e são lançadas em uma espécie de fossa, onde a parte sólida decanta e a parte líquida segue caminho. Os moradores relataram que de tempos em tempos um caminhão é enviado para realizar a limpeza da fossa. O líquido residual desce para uma pequena caixa que parece conter o sólido que, porventura, veio a cair e também serve para diminuir a velocidade da água que é lançada em um tanque de concreto, com plantas aquáticas que auxiliam na depuração da matéria orgânica presente na água. Dentro deste tanque, foi possível ver pneus, britas de diferentes espessuras e areia. Este é o último processo até que a água seja devolvida ao rio. A água estava sendo lançada diretamente em uma vala mais à frente e aos nossos olhos e olfato não pareceu limpa. De acordo com a empresa Águas do Imperador, que também é responsável pelo tratamento das águas, trata-se de uma fossa séptica com filtro anaeróbio, com uma zona de raízes, lançada em uma vala de infiltração.

Percebe-se que a água, na mesma comunidade, passa por um manejo diferenciado, como mostra a Figura 4, um croqui que aponta os movimentos das águas na Tapera reassentada. Agora toda a água da nascente é retida, de forma que um córrego deixa de seguir o percurso que é visto no ciclo hidrológico. A partir da construção da rede hidráulica das novas casas, a água passa por outro caminho construído e é estocada (apenas o excedente é drenado para o rio ${ }^{13}$ ),

12 Corresponde a maior parte das águas residuais domésticas.

13 Ou apenas infiltre já que não possui vazão suficiente para manter um córrego já que apenas o excesso é dispensado. 


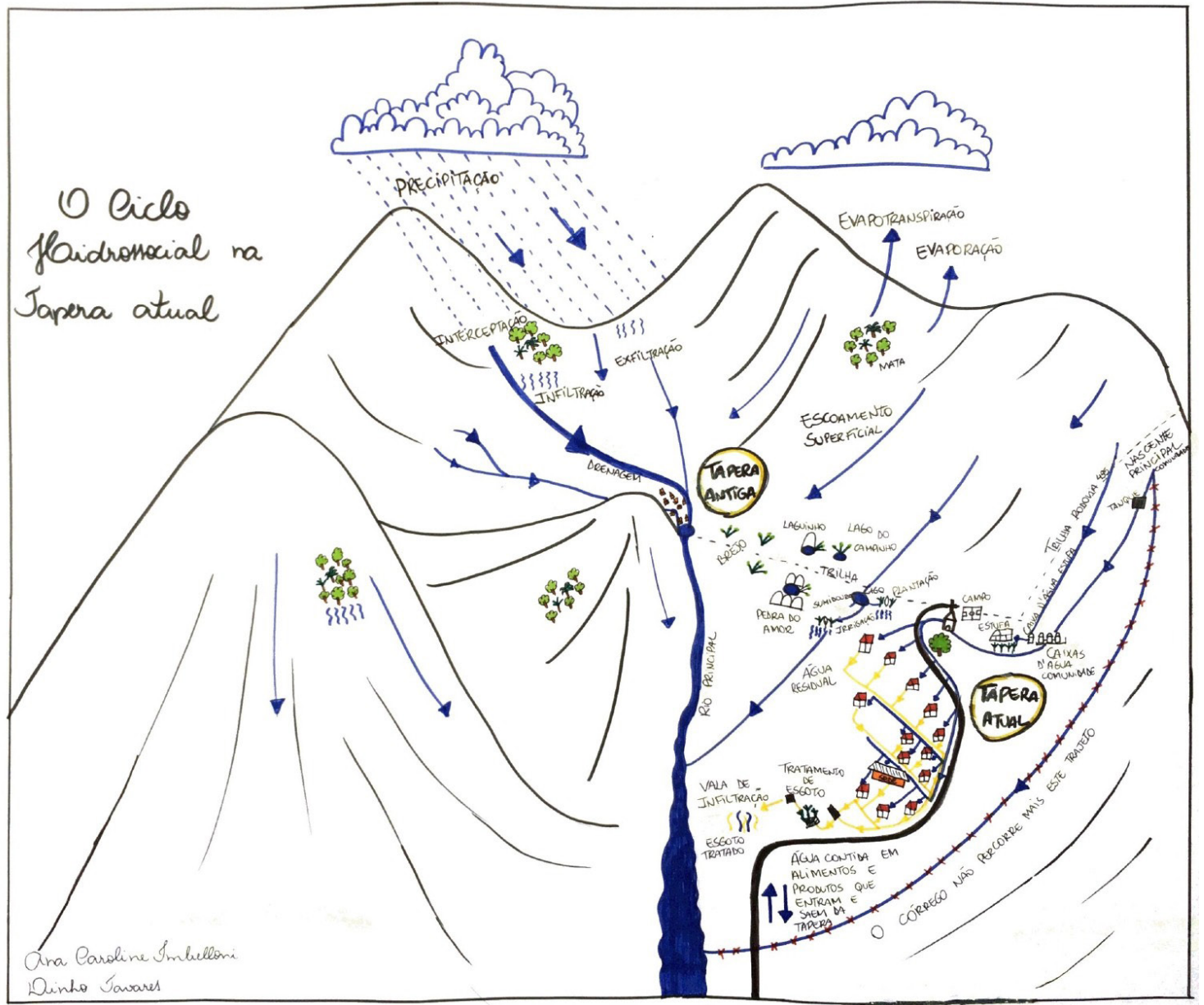

Fonte: elaborado por Dinho Tavares e pela própria autora, abril de 2019.

passando a ser liberada de acordo com o uso da população, no abrir e fechar das torneiras. Ela não corre mais livremente pelo córrego (que era perene) até alcançar ao rio principal da bacia. Passa em forma encanada por um circuito de casas para só depois partir e ser lançada na vala de infiltração, podendo então chegar ao rio (ou não).

É relevante pontuar que, nas poucas plantações ${ }^{14}$ ainda realizadas na Tapera, os moradores utilizam água das nascentes próximas a essas para irrigação, não havendo problema em usar qualquer nascente do território. Após a utilização da água por meio da irrigação, que é um movimento social, parte dela segue o caminho físico onde acaba infiltrando, evaporando, evapotranspirando e outra parte segue o fluxo até o rio.

Swyngedouw (1997, 1999) fala sobre a importância de compreender que a circulação da água é um processo social e físico combinado, sendo relevante conseguir trazer esses movimentos hidrossociais à visibilidade. Hoje, a maior parte da comunidade não vê mais a água como antes (isso

14 Devido à dificuldade de escoar a produção e diante do condomínio de alto padrão que se interpôs entre a comunidade e a estrada principal, a comunidade, há cerca de 50 anos, passou a oferecer sua mão de obra para os moradores do condomínio e assim trabalham como jardineiros, cozinheiras, domésticas, entre outros. literalmente), não precisa atravessar a ponte, não mora perto do rio, não passa pelos caminhos frequentemente úmidos por causa das nascentes próximas, não tem mais a água correndo durante todo dia pelo seu quintal, passando a ter novas características, diferentes das que tradicionalmente tiveram.

Surpreendentemente, pelo motivo das águas e da sua força, a nova forma da Tapera lidar com ela mudou, começando pelo manejo. O ciclo hidrossocial disponibiliza lentes para que seja possível olhar esses novos fluxos com novos olhos, o que para o ciclo hidrológico passaria despercebido.

Este afluente que mudou de direção e de fluxo não nutre mais o rio diretamente. Em longo prazo, pode trazer mudanças mais a jusante com a diminuição da vazão do rio principal, ficando cada vez mais dependente da água subterrânea. O ciclo hidrossocial permite um olhar mais atento a essas mudanças, inserindo seres humanos como mais um dos componentes dos movimentos das águas.

Swyngedouw $(2005,2006)$ nos traz muitas reflexões acerca de como a água e a relação de poder são intrínsecas. Na Tapera, a partir deste olhar político, foram observadas 
questões de poder mais equilibradas, no que se refere a possíveis disputas com relação à água, evidenciando um ambiente comunitário onde não são necessárias disputas de força entre interesses distintos.

\section{Considerações finais}

Este olhar sobre as relações sociais e as águas é um tema muito relevante e relativamente recente, o que certamente o faz desafiador. O ciclo hidrossocial ainda é muito conceitual, sem um percurso metodológico claramente definido, o que gera um grande desafio em aplicá-lo, mas este é um começo. Optou-se por trabalhar com três técnicas: comunicação participativa, cartografia social e caminhada guiada, que se complementaram e colaboraram para se chegar em algum entendimento sobre o ciclo hidrológico na Tapera.

Como Bakker (2012) diz, há um processo de moldagem mútua entre a água e as relações sociais, deixando bem claro que ela não é inerte a essas mudanças, na verdade, se dão mutuamente, fazendo e refazendo as relações sociais. Observa-se, de forma marcante, como a água teve e tem um papel ativo nas formações sociais da comunidade da Tapera. A água é co-protagonista junto ao povo nessas transformações.

É de riquíssima importância compreender que os rios e as águas faziam e fazem parte da comunidade, mesmo hoje sendo de forma tão diferente. É a partir dela que ocorre a manutenção da vida e, assim, das relações sociais. Os moradores sabem onde tem água e onde não tem de forma muito clara, inclusive sabem da nascente que dá água no período mais seco e no período mais úmido. A comunidade possui uma noção espacial muito interessante do seu território, com muitas memórias e histórias.

Percebemos a mudança do ciclo hidrossocial da comunidade, que antes tinha uma relevante soberania hídrica, com a possibilidade de escolher dentre os diversos cursos d'água que chegavam próximos às suas casas, o que melhor lhe aprouvesse. Parte do curso d'água era desviado para seus quintais e retornava em um momento seguinte para o rio, o que lhes proporcionava um maior contato, inclusive visual, com as águas e com o lugar onde viviam.

Hoje, após as mudanças de localidade e após a implantação de um sistema de abastecimento por agentes externos à comunidade, passaram a ter uma relação mais afastada com a água (apesar dos próprios, por conhecer muito bem suas terras e suas nascentes, terem escolhido o curso para serem abastecidos por suas águas). O novo ciclo hidrossocial da Tapera pode até comprometer a segurança hídrica comunitária, uma vez que passaram a depender de apenas uma nascente para abastecer as 65 pessoas que ali vivem (que, paradoxalmente, é ricamente drenada). Felizmente, desde o tempo em que chegaram ao reassentamento não tiveram problemas de escassez hídrica.

Após o barramento completo da água, a nascente deixa de fluir para o rio, passando a ter um novo caminho. Depois de estocada, ela passa por dentro das casas (podendo ser novamente estocada), em um pequeno contato com os moradores e logo sai pelo ralo. Após o sistema de tratamento de esgoto, é lançada na vala para, só então, poder ter contato com o rio pelo lençol freático. Então, para as bases de dados hidrográficos o rio estaria fluindo por um caminho determinado pela gravidade e pela forma do terreno, mas, socialmente, conseguimos perceber que este rio foi remanejado. Com o ciclo hidrossocial, é possível perceber que este rio segue outro caminho, encanado e passando dentre as casas, um caminho construído socialmente. Além disso, o contato das pessoas com a nova forma que a água chega foi alterado, logo, seus fazeres diários também.

Com isso, percebemos que os ciclos hidrossociais existentes podem ser diversos e se modificam a cada localidade, a cada forma de vida, de manejo, de ambiente, trazendo à luz a importância desse olhar mais aprofundado sobre os lugares em que as águas e seus movimentos sociais e físicos estão. 
ALMEIDA, Alfredo Wagner Berno de. (2013) Nova Cartografia Social da Amazônia. In: ALMEIDA, Alfredo Wagner Berno de; FARIAS JÚNIOR, Emmanuel de Almeida (Org.). Povos e comunidades tradicionais: Nova Cartografia Social. Manaus: Cnpq, p. $28-34$. Disponível em: <http://novacartografiasocial.com.br/download/povos-e-comunidades-tradicionais-nova-cartografia-social/>. Acesso em: 25 maio 2018.

BAKKER, Karen. (2012) Water: Political, biopolitical, material. Social Studies Of Science, Vancouver, v. 42, n. 4, p.616-623. SAGE Publications. http://dx.doi.org/10.1177/0306312712441396. Disponível em: <http://journals.sagepub.com/doi/ pdf/10.1177/0306312712441396>. Acesso em: 07 jun. 2017.

BEAR, Christopher; BULL, Jacob. (2011) Guest Editorial. Environment And Planning A, [s.l.], v. 43, n. 10, p.2261-2266, out. 2011. SAGE Publications. http://dx.doi.org/10.1068/a44498. Disponível em: <http://journals.sagepub.com/doi/pdf/10.1068/a44498>. Acesso em: 10 jun. 2017.

BUDDS, Jessica. (2009) Contested H2O: science, policy and politics in water resources management in Chile. Geoforum vol. 40, n. 3 p. $418-430$.

BUDDS, Jessica, HINOJOSA, Leonith. (2012) Restructuring and rescaling water governance in mining contexts: the co-production of waterscapes in Peru. Water Alternatives, vol. 5, n. 1, p.119-137.

BUDDS, Jessica. (2012) La demanda, evaluación y asignación del agua en el contexto de escasez: un análisis del ciclo hidrosocial del valle del río La Ligua, Chile. Revista de Geografía Norte Grande, [s.l.], n. 52, p.167-184, set. 2012. SciELO Comision Nacional de Investigacion Cientifica Y Tecnologica (CONICYT). http://dx.doi.org/10.4067/s0718-34022012000200010. Disponível em: <http://www.scielo.cl/scielo.php?pid=S071834022012000200010\&script=sci_abstract.Acesso em: 10 ago. 2017.

FELIPPE, Miguel Fernandes. (2010) La Geografía Del Ciclo Hidrosocial: Un Abordaje Crítico. In: Boletín GSF. Geógrafos Sem Fronteiras, p. 6-8.

GARSKE, Lindalva Maria Novaes. (2016) Metodologia da Investigação Comunicativa: um estudo sobre suas bases teóricometodológicas. 2016. 79 f. Relatório final de Pós-Doutorado (Pós Doutorado) - Curso de Educação, Programa de Pós-Graduação em Educação, Universidade Federal de Mato Grosso, Rondonópolis.

HABERMAS, Jürgen. (1999) Teoría de la Acción Comunicativa, I: Racionalidad de la acción y racionalización social. Madrid: Taurus Humanidades (publicado originalmente en 1981).

IMBELLONI, Ana Caroline Pinheiro; FELIPPE, Miguel Fernandes. (2017) Compreendendo o Ciclo Hidrossocial em Comunidades Quilombolas: possibilidades metodológicas para o estudo. VIII Simpósio Internacional de Geografia Agrária e IX Simpósio Nacional de Geografia Agrária; Nov.2017; Curitiba, ISSN: 1980-4555, p.1-10.

INPE. Acesso aos dados pluviométricos da estação pluviométrica do Parque Nacional de Teresópolis no dia 11 de janeiro de 2011. Disponível em: http://www.inmet.gov.br/portal/index.php?r=bdmep/bdmep. Acessado em: 02 de março de 2020.

LIMA, Widney P.; RAMOS, João D. D.; SILVA, Cristhiano K. Da. (Org.) (2013)Entrevista com o professor Alfredo Wagner Almeida. Espaço Ameríndio, Porto Alegre, v. 7, n. 2, p.254-270. Semestral.

LINTON, James. (2006) What is Water?: The History and Crisis of a Modern Abstraction. Ottawa: Heritage Branch, 456 p. (ISBN: 978-0-494-23294-1). Disponível em: <https://curve.carleton.ca/system/files/etd/4570d131-bfce-4c83-aaa9-2d2bcb64068f/ etd_pdf/a37d3ae4e286deb22f765aa6be2470b3/linton-whatiswaterthehistoryandcrisisofamodernabstraction.pdf>. Acesso em: 01 set. 2017.

LINTON, James; BUDDS, Jessica. (2014) The hydrosocial cycle: Defining and mobilizing a relational-dialectical approach to water. Geoforum, v. 57, p. 170-180.

MEIRELES, Antônio Jeovah de Andrade;SOUZA, Wallason Farias de; LIMA, Ana Paula da Silva.(2016) Atlas Socioambiental: cartografia social das comunidades de Icapuí. Fortaleza: Fundação Brasil Cidadão, 146 p.

MELO, Roseli Rodrigues de. (2006) Metodologia de Investigação Comunicativa: contribuições para a pesquisa educacional na construção de uma escola com e para todas e todos. 29a Reunião anual, Andep, [s.l.], 17 p. Disponível em: <http://www.anped. org.br/sites/default/files/gt03-2096.pdf>. Acesso em: 10 maio 2018.

PORTO-GONÇALVES, Carlos Walter. (2013) O meio ambiente como mercadoria V: as contradições entre a teoria e a prática. In: $A$ Globalização da Natureza e a Natureza da Globalização. 5aed, Rio de Janeiro: Civilização Brasileira, p.413-447.

SWYNGEDOUW, Erik. (1997). Power, nature and the city. The conquest of water and the political ecology of urbanization in Guayaquil, Ecuador: 1880-1990. Environment and Planning A 29, 311-332.

, Erik. (1999). Modernity and hybridity: nature, regeneracionism, and the production of the Spanish waterscape, 18901930. Annals of the Association of American Geographers 89 (3), 443-465.

Erik. (2006). Power, Water and Money: Exploring the Nexus. United Nations Development Program. Human Development 
Report Office, Occasional Paper 2006/14.

, Erik. (2005). Dispossessing H 2 O: the contested terrain of water privatization. Capitalism Nature Socialism, [s.I.], v. 16, n. 1, p.81-98, 1 mar. 2005. Informa UK Limited. http://dx.doi.org/10.1080/1045575052000335384. Disponível em:<http://www. tandfonline.com/doi/abs/10.1080/1045575052000335384?journalCode=rcns20>. Acesso em: 25 maio 2017.

, Erik. (2009). The political economy and political ecology of the hydrosocial cycle. Universities Council on Water Resources Journal of Contemporary Water Research and Education 142, 56-60.

TUNDISI, José Galizia. (2003) Ciclo hidrológico e gerenciamento integrado. In: Gestão das Águas, Ciência e Cultura, Out./Dez. vol.55, no.4, p. 31-33. 